\title{
SOSIALISASI DAN PENERAPAN EDINBURGH POSTNATAL DEPRESSION SCALE (EPDS) OLEH BIDAN DALAM UPAYA DETEKSI DINI DEPRESI PADA IBU POSTPARTUM DI PUSKESMAS KOTA PEKANBARU
}

\author{
${ }^{1)}$ Lailiyana, ${ }^{2)}$ Elly Susilawati \\ ${ }^{1,2)}$ Program Studi D4 Kebidanan, Jurusan Kebidanan, Poltekkes Kemenkes Riau \\ 1,2) Jl. Melur No $103 \mathrm{Kec}$ Sukajadi Kota Pekanbaru - Riau - Indonesia \\ E-mail : Lailiyana_skm@yahoo.co.idellysusilawatiramli@gmail.com
}

\begin{abstract}
ABSTRAK
Depresi postpartum berdampak mengurangi kebahagiaan, mempengaruhi hubungan ibu dan anak dan membahayakan jiwa ibu dan bayi sampai menyebabkan kematian. Salah satu upaya mencegah depresi postpartum adalah dengan melakukan deteksi dini menggunakan Edinburgh Postnatal Depresion Scale (EPDS). Tujuan dilakukannya kegiatan pengabdian kepada masyarakat ini adalah melakukan sosialisasi tentang EPDS bagi bidan dan menggerakkan bidan untuk menerapkan EPDS sebagai alat bantu melakukan skrining dalam upaya deteksi dini masalah psikologis pada ibu postpartum di wilayah kerja Puskesmas Sidomulyo Pekanbaru Tahun 2019. Metode kegiatan pengabdian masyarakat ini dilakukan dengan cara melakukan sosialisasi EPDS kepada bidan dilanjutkan dengan monitoring dan evaluasi terhadap penerapan EPDS oleh bidan. Hasil kegiatan pengabdian kepada masyarakat ini adalah telah dilaksanakan kegiatan sosialisasi EPDS kepada bidan di Aula Puskesmas Sidomulyo. Berdasarkan hasil monitoring dan evaluasi didapatkan peningkatan penerapan EPDS oleh bidan untuk deteksi dini masalah psikologis ibu postpartum yaitu dari 66,7 menjadi 88,9. Disarankan kepada bidan dapat meningkatkan lagi upaya deteksi dini depresi postpartum pada setiap ibu postpartum dengan menggunakan EPDS baik pada saat kunjungan rumah maupun saat klien berkunjung ke fasilitasi pelayanan
\end{abstract}

Kata Kunci: Edinburgh Postnatal Depression Scale (EPDS), Depresi Post partum, Deteksi Dini

\begin{abstract}
Postpartum depression has the effect of reducing happiness, affecting the relationship of mother and child and endangering the life of the mother and baby, even causing death. One effort to prevent postpartum depression is by early detection using the Edinburgh Postnatal Depression Scale (EPDS). The purpose of this community service activity was to socialize EPDS to midwives and to encourage midwives to apply EPDS as a screening tool in an effort to detect psychological problems in postpartum mothers earlier in the working area of Sidomulyo Health Center Pekanbaru in 2019. This method of community service activities was carried out with socialization of EPDS to midwives followed by monitoring and evaluation of the implementation of EPDS by midwives. The results of this community service activity were EPDS socialization activities for midwives in the Sidomulyo Community Health Center Hall had conducted. Based on the results of monitoring and evaluation, there was an increase in the implementation of EPDS by midwives for early detection of postpartum maternal psychological problems, namely from 66,7 to 88,9. It is suggested to midwives to increase the efforts of early detection of postpartum depression in each postpartum mother by using EPDS both at home visits and when clients visit health care facility
\end{abstract}

Keyword: Edinburgh Postnatal Depression Scale (EPDS), Post Partum Depression, Early Detection

\section{PENDAHULUAN}

\section{Sub Judul}

Diperkirakan sekitar 50-70\% ibu melahirkan menunjukkan gejala-gejala awal kemunculan depresi postpartum, walau demikian gejala tersebut dapat hilang secara perlahan karena proses adaptasi dan dukungan keluarga yang tepat [1] [2]. Depresi post partum merupakan gangguan alam perasaan (mood) yang dialami oleh ibu pasca persalinan akibat kegagalan dalam penerimaan proses adaptasi psikologis. Kasus depresi post partum ini sudah banyak dilaporkan dengan tingkat insiden yang bervariasi. [3] menyatakan tingkat insiden kasus depresi post partum yang berbeda di beberapa negara seperti di Kolumbia $(13,6 \%)$, Dominika (3\%), dan Vietnam $(19,4 \%)$. [4]melaporkan hasil penelitian dari O'Hara dan Swain bahwa kasus depresi post partum masih banyak terjadi di beberapa negara maju seperti di Belanda (2\%-10\%), Amerika Serikat (8\%-26\%), dan Kanada (50\%-70\%). 
[5] melaporkan angka kejadian depresi postpartum di Asia cukup tinggi dan sangat bervariasi antara 26-85\%, sedangkan di Indonesia angka kejadian depresi postpartum antara 50$70 \%$ dari wanita pasca persalinan, insiden kasus depresi post partum bervariasi yaitu di Bandung mencapai 30\% (2002), Medan mencapai 48,4\% (2009), dan Jakarta mencapai 76\% (2010).

Pada suatu penelitian di USA, 391 ibu diikutkan dalam suatu kelompok skrining postpartum, dimana Edinburgh Postnatal Depression Scale (EPDS) digunakan, atau kelompok kontrol yang terdiri dari deteksi spontan melalui pemeriksaan klinis rutin. Sesuai yang diharapkan, insidensi deteksi gejala depresi secara signifikan lebih tinggi pada kelompok skrining dari pada kelompok yang terdeteksi secara spontan $(35.4 \%$ vs. $6.3 \% ; \mathrm{p}<0.001)$ [1] [6]. EPDS ialah salah satu metode untuk mendeteksi depresi pasca persalinan. Walaupun tidak umum, EPDS dapat dengan mudah digunakan selama 6 minggu pasca persalinan [7] [8].

Hasil wawancara dari survey pendahuluan dengan bidan koordinator di Puskesmas Sidomulyo menyatakan bahwa, laporan bulanan persalinan dan KIA dari Klinik Pratama dan BPM belum melengkapi format keadaan psikologis ibu postpartum. Format keadaan psikologis ibu postpartum pada laporan bulanan persalinan selalu kosong, dengan alasan tidak dilakukan pengkajian karena tidak ada instrumen pengukurannya. Berdasarkan hal tersebut diatas, maka untuk kegiatan pengabdian kepada masyarakat tahun 2019 penulis tertarik ingin melanjutkan sosialisasi tentang Edinburgh Postnatal Depression Scale (EPDS) pada bidan di wilayah kerja Puskesmas Sidomulyo, melalui kegiatan ini diharapkan dapat menggerakkan bidan untuk menerapkan EPDS sebagai alat bantu dalam melakukan skrining deteksi dini masalah psikologis pada ibu postpartum.

\section{METODE PELAKSANAAN}

Kegiatan Pengabdian Masyarakat ini dilaksanakan pada bulan April sampai Juli 2019. Lokasi dilaksanakan di Wilayah kerja Puskesmas Sidomulyo dan Puskesmas Sidomulyo Rawat Inap Kota Pekanbaru

a. Melakukan pertemuan dengan bidan di Puskesmas Sidomulyo dan Puskesmas Sidomulyo Rawat Inap pada tanggal 14 - 15 Juni 2019 untuk menentukan pertemuan berikutnya sekaligus sosialisasi dan penerapan EPDS

b. Melakukan sosialisasi dan Penerapan EPDS kepada bidan pada tanggal 3 Juli 2019 bertempat di Klinik Sarinah Wilayah Kerja Puskesmas Sidomulyo Kota Pekanbaru.

c. Melakukan sosialisasi dan Penerapan EPDS kepada bidan pada tanggal 16 Juli 2019 bertempat di Aula Puskesmas Sidomulyo Rawat Inap Kota Pekanbaru

d. Melakukan monitoring dan Evaluasi penerapan EPDS oleh bidan yaitu pada tanggal 24 Juli 2019 di Puskesmas, BPM, Rumah Bersalin yang berada di wilayah kerja Puskesmas Sidomulyo.

e. Melakukan monitoring dan Evaluasi penerapan EPDS oleh bidan yaitu pada tanggal 25 Juli 2019 di Puskesmas Sidomulyo Rawat Inap Kota Pekanbaru.

\section{Kerangka Kerja Pengabdian}

Untuk mempermudah dalam kegiatan pengabdian ini, maka penulis membuatkan kerangka kerja kegiatan seperti pada gambar 1 berikut ini. 


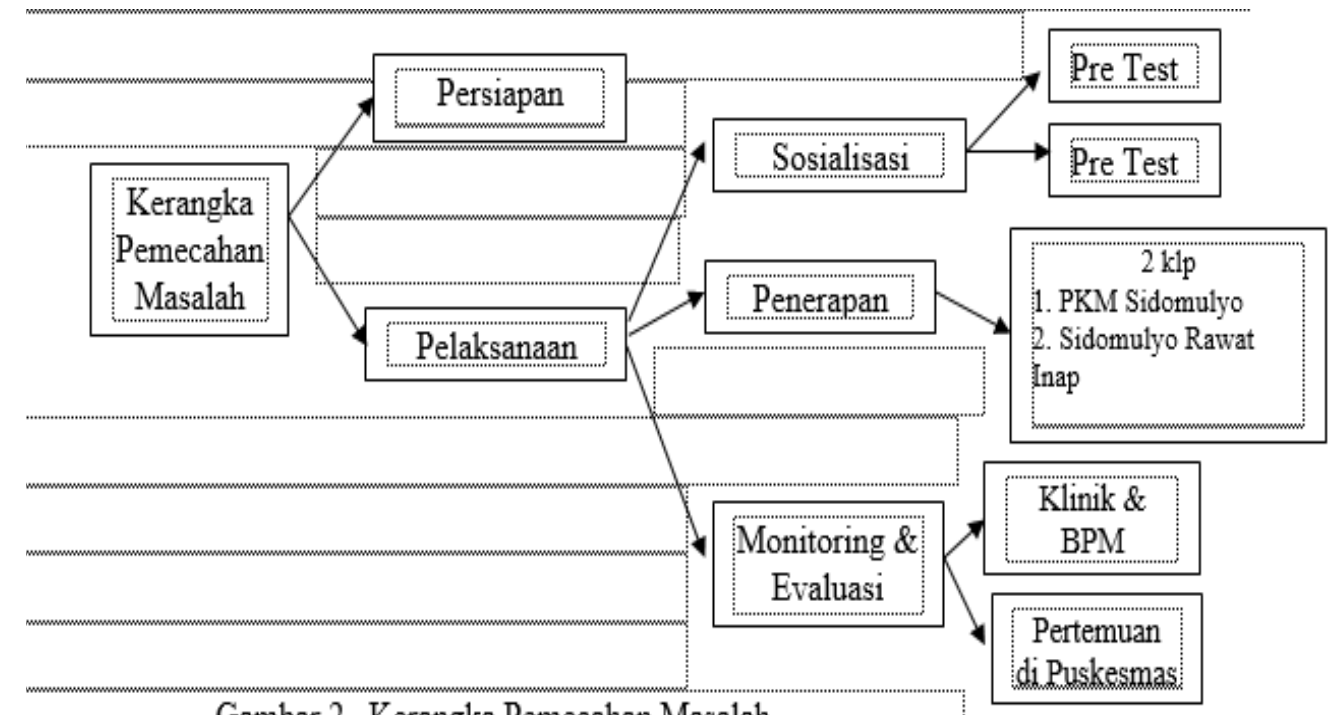

Gambar 1. Kerangka Kerja Kegiatan Pengabdian

\section{HASIL}

Pelaksanaan kegiatan pengabdian kepada masyarakat tentang Sosialisasi dan penerapan Edinburgh Postpartum Depression Scale (EPDS) oleh Bidan di Puskesmas Sidomulyo dan Puskesmas Sidomulyo Rawat Inap telah dilaksanakan melalui tahapan yaitu Melakukan pertemuan dengan bidan di Puskesmas Sidomulyo dan Puskesmas Sidomulyo Rawat Inap pada tanggal 14 15 Juni 2019 untuk menentukan pertemuan berikutnya sekaligus sosialisasi dan penerapan EPDS, selanjutnya sosialisasi dan Penerapan EPDS kepada bidan dilakukan pada tanggal 3 Juli 2019 bertempat di Klinik Sarinah Wilayah Kerja Puskesmas Sidomulyo Kota Pekanbaru dengan jumlah bidan yang hadir 18 orang dan pada tanggal 16 Juli 2019 bertempat di Aula Puskesmas Sidomulyo Rawat Inap Kota Pekanbaru dengan jumlah bidan yang hadir 35 orang. Monitoring dan Evaluasi penerapan EPDS oleh bidan dilakuka pada tanggal 24 Juli 2019 di Puskesmas, BPM, Rumah Bersalin yang berada di wilayah kerja Puskesmas Sidomulyo, sedangkan monitoring dan evaluasi di Puskesmas Sidomulyo Rawat Inap dilakukan pada tanggal 25 Juli 2019. Hasil kegiatan sosialisasi dan penerapan EPDS dapat dilihat pada tabel-tabel berikut.

\section{Tabel 1.}

Gambaran Pengetahuan Bidan tentang EPDS Sebelum Sosialisai EPDS Di Wilayah Kerja Puskesmas Sidomulyo dan Puskesmas Sidomulyo Rawat Inap

Kota Pekanbaru Tahun 2019

\begin{tabular}{|c|l|c|c|c|c|c|}
\hline No & Pengetahuan & \multicolumn{2}{|c|}{ PKM Sidomulyo } & PKM & $\begin{array}{c}\text { Rawat } \\
\text { Inap }\end{array}$ & Total \\
\hline 1 & $\begin{array}{l}\text { Pernah } \\
\text { mendengar/tahu }\end{array}$ & 5 & 27,8 & 10 & 28,6 & 15 \\
\hline 2 & $\begin{array}{l}\text { Tidak pernah } \\
\text { mendengar/tidak } \\
\text { tahu }\end{array}$ & 13 & 72,2 & 25 & 71,4 & 38 \\
\hline & Jumlah & 18 & 100,0 & 35 & 100,0 & 53 \\
\hline
\end{tabular}

Pada tabel 1 dapat dilihat bahwa Pengetahuan bidan tentang EPDS secara umum sebelum dilakukan sosialisasi EPDS, Pada Puskesmas Sidomulyo sebagian besar (72,2 \%) tidak pernah mendengar tentang EPDS sama halnya pada Puskesmas Sidomulyo Rawat Inap sebagian besar bidan yaitu $(71,4 \%)$ tidak pernah mendengar tentang EPDS/tidak tahu. 
Tabel 2.

Perbandingan rata-rata nilai Pengetahuan Bidan tentang EPDS berdasarkan Hasil Pretest dan Post test Di Wilayah Kerja Puskesmas Sidomulyo dan Puskesmas Sidomulyo Rawat Inap Kota Pekanbaru Tahun 2019

\begin{tabular}{|c|c|c|c|c|c|c|}
\hline No & $\begin{array}{c}\text { Pengetahuan } \\
\text { tentang EPDS }\end{array}$ & PKM & Sidomulyo & PKM & $\begin{array}{c}\text { Rawat } \\
\text { Inap }\end{array}$ & Total \\
\hline & & $\mathrm{n}$ & Mean & $\mathrm{n}$ & Mean & $\mathrm{N}$ \\
\hline 1 & Pretest & 18 & 66,7 & 35 & 62,6 & 53 \\
\hline 2 & Post test & 18 & 88,9 & 35 & 85,1 & 53 \\
\hline
\end{tabular}

Pada tabel 2 dapat dilihat bahwa rata-rata nilai pengetahuan bidan tentang EPDS sebelum dan sesudah dilakukan sosialisasi tentang EPDS mengalami peningkatan yaitu di Puskesmas Sidomulyodari rata-rata nilai 66,7 menjadi rata-rata 88,9 sedangkan di Puskesmas Sidomulyo Rawat Inap rata-rata nilai 62,6 menjadi 85,1.

Tabel 3.

Distribusi Bidan berdasarkan Tempat Pelayanan Kebidanan Di Wilayah Kerja Puskesmas Sidomulyo dan Puskesmas Sidomulyo Rawat Inap Kota Pekanbaru Tahun 2019

\begin{tabular}{clcc}
\hline No & \multicolumn{1}{c}{ Tempat Pelayanan } & $\mathrm{n}$ & $\%$ \\
\hline 1 & Puskesmas & 12 & 22,6 \\
\hline 2 & Klinik Swasta & 11 & 20,7 \\
\hline 3 & Bidan Praktik Mandiri & 18 & 33.9 \\
\hline 4 & Swasta/RS & 12 & 22,6 \\
\hline & Jumlah & 53 & 100,0 \\
\hline
\end{tabular}

Pada tabel 3 dapat dilihat bahwa sebagian besar bidan memberikan pelayanan kebidanan di Bidan Praktik Mandiri Sebesar 33,9 \%

Tabel 4.

Distribusi Bidan berdasarkan Penerapan EPDS Sebelum dilakukan Sosialisasi EPDS Di Wilayah Kerja Puskesmas Sidomulyo dan Puskesmas Sidomulyo Rawat Inap Kota Pekanbaru Tahun 2019

\begin{tabular}{ccccccc}
\hline No & $\begin{array}{c}\text { Penerapan } \\
\text { EPDS }\end{array}$ & PKM & Sidomulyo & PKM & $\begin{array}{c}\text { Rawat } \\
\text { Inap }\end{array}$ & Total \\
\hline & nenerapkan & 0 & 0 & $n$ & $\%$ & \\
\hline 1 & Merak & 18 & 33,9 & 35 & 66,1 & 53 \\
\hline 2 & $\begin{array}{c}\text { Tidak } \\
\text { menerapkan }\end{array}$ & & 0 & 0 & 0 \\
\hline
\end{tabular}

Pada tabel 4 dapat dilihat bahwa sebelum dilakukan sosialisasi EPDS seluruh (100\%) bidan baik di Puskesmas Sidomulyo dan Puskesmas Sidomulyo Rawat Inap tidak menerapkan EPDS untuk deteksi dini masalah psikologi ibu postpartum

Tabel 5.

Distribusi Bidan berdasarkan Penerapan EPDS Setelah dilakukan Sosialisasi EPDS Di Wilayah Kerja Puskesmas Sidomulyo dan Puskesmas Sidomulyo Rawat Inap Pekanbaru

\begin{tabular}{ccccccc}
\hline No & $\begin{array}{c}\text { Penerapan } \\
\text { EPDS }\end{array}$ & PKM & Sidomulyo & PKM & $\begin{array}{c}\text { Rawat } \\
\text { Inap }\end{array}$ & Total \\
\hline & & $\mathrm{n}$ & $\%$ & $\mathrm{n}$ & $\%$ & \\
\hline 1 & Menerapkan & 11 & 61,11 & 20 & 57,14 & 31 \\
\hline 2 & $\begin{array}{c}\text { Tidak } \\
\text { menerapkan }\end{array}$ & 7 & 38,89 & 15 & 42,86 & 22 \\
\hline
\end{tabular}




\begin{tabular}{rrrrrr}
\hline Jumlah & 18 & 100.0 & 35 & 100,0 & 53 \\
\hline
\end{tabular}

Pada tabel 5. dapat dilihat bahwa setelah dilakukan sosialisasi EPDS sebagian besar $(61,11$ \%) bidan telah menerapkan EPDS dalam deteksi dini masalah psikologi ibu postpartum di Puskesmas Sidomulyo, sama halnya dengan Puskesmas Sidomulyo Rawat Inap sebagian besar $(57,14 \%)$ bidan telah menerapkan EPDS dalam deteksi dini masalah psikologi ibu postpartum.

Berdasarkan hasil dari pelaksanaan kegiatan sosialisasi dan penerapan Edinburgh Postnatal Depression Scale (EPDS) oleh bidan di wilayah kerja Puskesmas Sidomulyo dan Puskesmas Sidomulyo Rawat Inap Kota Pekanbaru untuk pengetahuan bidan tentang EPDS sebagaimana yang dijelaskan pada tabel 3.2 dapat dilihat bahwa pada Puskesmas Sidomulyo Pekanbaru didapatkan rata-rata nilai 66,7 pada saat pretest, dan mengalami peningkatan pengetahuan tentang EPDS pada saat posttest dengan nilai rata-rata 88,9. Pada Puskesmas Sidomulyo Rawat Inap Kota Pekanbaru rata-rata nilai pretest sebelum dilakukan sosialisasi EPDS adalah 62,6 dan sesudah dilakukan sosialisasi tentang EPDS mengalami peningkatan pengetahuan dengan rata-rata nilai 85,1 . Hal ini membuktikan bahwa sosialisasi sangat penting dilakukan untuk menambah pengetahuan dan wawasan bidan tentang metode baru yang sebelumnya belum pernah diketahui oleh bidan.

Pada tabel 4 dan tabel 5 dapat dilihat bahwa sebelum dilakukan sosialisasi EPDS seluruh (0 \%) bidan tidak menerapkan EPDS dalam deteksi dini masalah psikologi ibu postpartum di Puskesmas Sidomulyo dan Puskesmas Sidomulyo Rawat Inap Kota Pekanbaru. Setelah dilakukan sosialisasi EPDS terjadi peningkatan persentase bidan yang menerapkan EPDS dalam deteksi dini masalah psikologi ibu postpartum yaitu di Puskesmas Sidomulyo 61,11 \% sudah menerapkan namun masih ada 38,89 \% yang belum menerapkan dengan alasan tidak punya banyak waktu untuk mengkaji pasien, sedangkan di Puskesmas Sidomulyo Rawat Inap yang sudah menerpkan EPDS sebanyak 57,14 \% sementara yang belum menerapkan sebanyak 42,86\%. Hal ini membuktikan bahwa dengan adanya kegiatan sosialisasi tentang EPDS para bidan terpapar dengan EPDS ditandai dengan meningkatnya pengetahuan sehingga dengan pengetahuan tersebut para bidan mengetahui manfaat EPDS dan termotivasi untuk menerapkan EPDS dalam rangka deteksi dini masalah posikologis ibu postpartum sehingga bila ada penyimpangan psikologis dapat segera diatasi yang tidak berlanjut kepada depresi postpartum bahkan psikosa postpartum yang lebih berat. Dengan demikian diharapkan bidan berkontribusi dalam menekan angka kejadian depresi postpartum yang akhirnya dapat meningkatkan kualitas hidup ibu dan bayi sehingga secara tidak langsung dapat menurunkan angka kesakitan dan kematian ibu dan bayi.

\section{Dokumentasi Kegiatan}
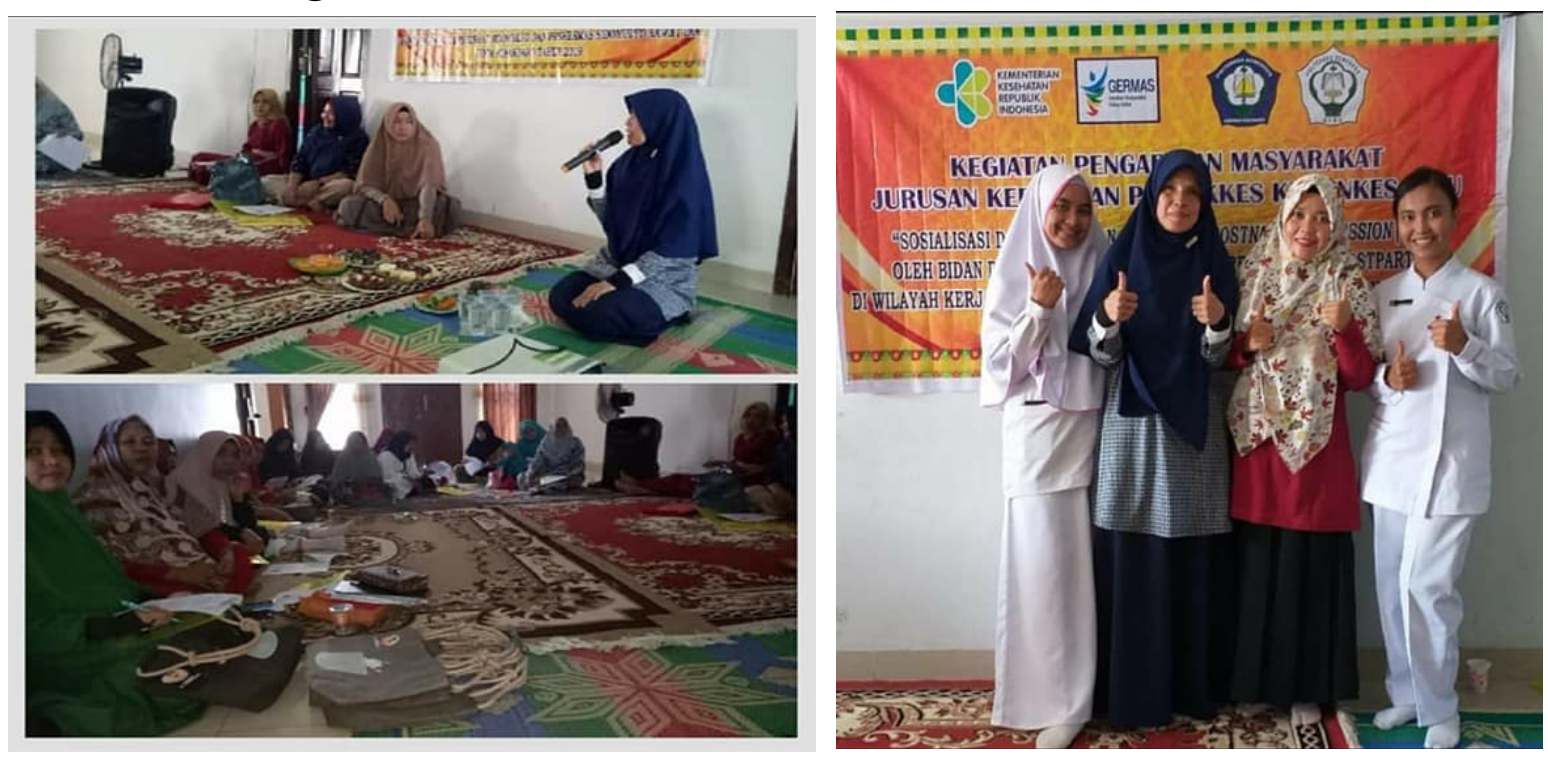


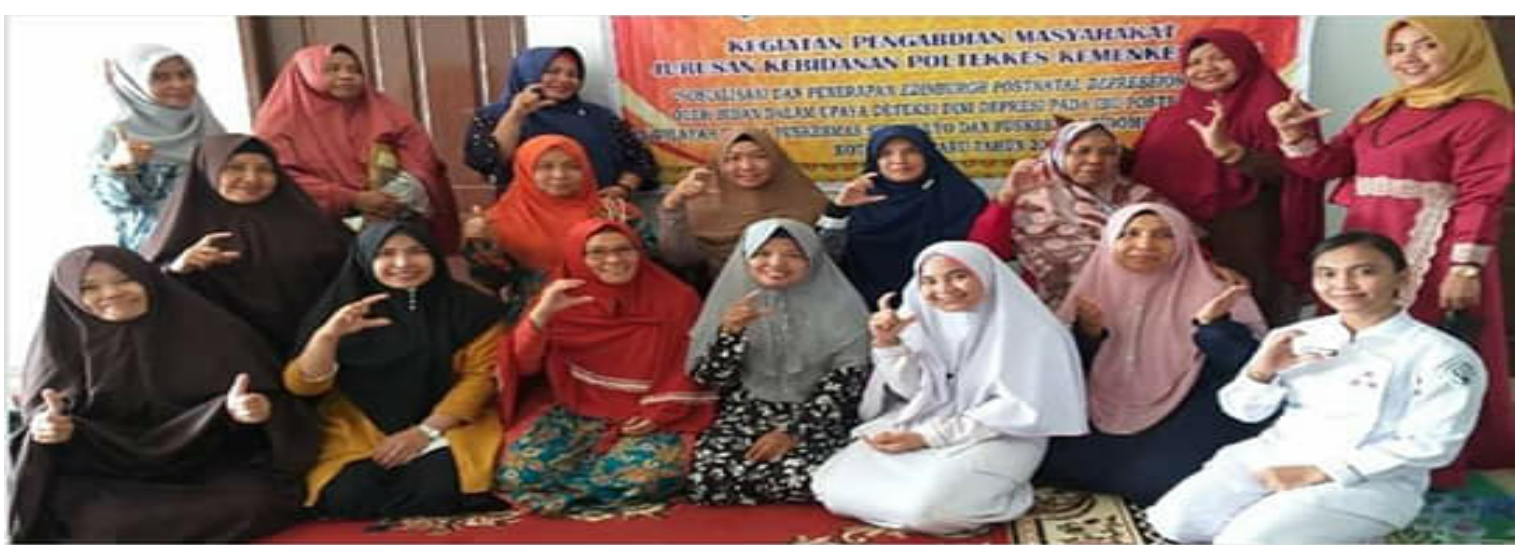

Gambar 1 : sosialisasi, penerapan dan monev EPDS

\section{KESIMPULAN}

Dari kegiatan Pengabdian kepada masyarakat tentang sosialisasi dan penerapan EPDS oleh bidan di wilayah kerja Puskesmas Sidomulyo dan Puskesmas Sidomulyo Rawat Inap Kota Pekanbaru dapat disimpulkan

a. Hasil pretest dan posttest, mengalami peningkatan pengetahuan peserta, yaitu pada Puskesmas Sidomulyo dari rata-rata 66,7 menjadi 88,9 dan di Puskesmas Sidomulyo Rawat Inap dari rata-rata nilai 62,6 menjadi rata-rata 85,1 .

b. Penerapan EPDS oleh bidan untuk deteksi dini masalah psikologis ibu postpartum mengalami peningkatan setelah dilakukan sosialisasi, Pada Puskesmas Sidomulyo dari $0 \%$ menjadi 61,11 \% dan pada Puskesmas Sidomulyo Rawat Inap dari 0\% menjadi 57,14\%.

\section{DAFTAR PUSTAKA}

[1] "Regina (5t90086), Hubungo Anha Depresi PosQartrm Dengan Kepuasan Seksral Pada lbu Primipra Skripsi Sarjana Strd \{ I, Fakultas Psikologi Univerritas Surabaya,”p. 90086, 1986.

[2] S. Saleha, Asuhan Kebidanan pada Ibu Nifas. Jakarta: Salemba Medika, 2009.

[3] J. P. Baxter, K. C. H. Fearon, and C. R. Pennington, "Clinical Practice 01: CLINICAL PRACTICE 01,” Br. J. Surg., vol. 89, no. S1, pp. 77-77, 2002.

[4] Soep, S. BS, and R. Sutatminingsih, "Pengaruh Intervensi Psikoedukasi Dalam Mengatasi Depresi Postpartum di RSU DR Pirngadi Medan," Ilmu Kesehat. Masy., vol. Magister K, p. 145, 2009.

[5] R. Clark, "W I SCO N S IN M ED I CAL JOU RN AL Postpartum Depression: Identification, Screening, and Treatment," no. February 2004, 2014.

[6] M. D. Bobak, LM, Lowdermilk, DL \& Jansen, Buku Ajar Keperawatan Maternitas. Jakarta.: EGC, 2004.

[7] P. Klainin and D. G. Arthur, "Postpartum depression in Asian cultures: A literature review," Int. J. Nurs. Stud., vol. 46, no. 10, pp. 1355-1373, 2009.

[8] Bahiyatun, Buku Ajar Asuhan Kebidanan Nifas Normal. Jakarta: Penerbit Buku Kedokteran, 2008. 